\title{
Chronic Kirschsteiniothelia infection superimposed on a pre-existing non- infectious bursitis of the ankle: the first case report of human infection
}

\author{
Masanori Nishi ${ }^{1 \dagger}$, Ichiro Okano ${ }^{1 * \dagger} \mathbb{B}$, Takatoshi Sawada', Yasuka Hara², Kiwamu Nakamura ${ }^{3}$, Katsunori Inagaki ${ }^{4}$ \\ and Takashi Yaguchi ${ }^{5+}$
}

\begin{abstract}
Background: Kirschsteiniothelia is a saprophytic fungus that is abundantly present in the environment. To date, there have been no reports of human infection caused by this fungus. We report a case of Kirschsteiniothelia infection superimposed on a pre-existing non-infectious bursitis of the ankle.

Case presentation: An 81-year-old immunocompetent female local farmer noticed the presence of a nodule on her right ankle 5 years before her first visit to our hospital. A cystic mass of approximately $45 \mathrm{~mm} \times 30 \mathrm{~mm}$ was present at the tip of the right lateral malleolus. Culture of the aspirated fluid revealed visibly black colonies and characteristic blackish hyphae; nucleotide sequence of the internal transcribed spacer region was determined and compared in a GenBank database. The results indicated Kirschsteiniothelia infection.

Conclusions: We described the first case of Kirschsteiniothelia infection manifested as ankle bursitis. The disease seemed to be localized and systemic antibiotics had not been used in this case. However, continued observation is needed because of the possibility of disease progression with the pathogen.
\end{abstract}

Keywords: Kirschsteiniothelia, Bursitis, Black fungus, Human infection

\section{Background}

Black fungus, or dematiaceous fungus, is a generic term used to describe fungi whose developing colonies exhibit a distinct black to grayish color by producing dark melanoid pigments on the cell walls of vegetative cells and/or conidia [1]. Black fungi are abundant in the environment, and over 60 genera and 300 species of black fungi exhibit pathogenicity to humans and animals [2]. However, Kirschsteiniothelia, known as a phytopathogenic fungus and the teleomorphic form of Dendryphiopsis, has never been reported to cause infections in humans. Here, we report the first confirmed case of Kirschsteiniothelia soft-tissue infection in humans.

\footnotetext{
* Correspondence: ichiro.okano.e31@gmail.com

${ }^{+}$Masanori Nishi, Ichiro Okano and Takashi Yaguchi are contributed equally to this work.

'Department of OrthopaedicSurgery, Ohta-Nishinouchi Hospital, 2-5-20

Nishinouchi, Koriyama, Fukushima 963-8558, Japan

Full list of author information is available at the end of the article
}

\section{Case presentation}

An 81-year-old female local farmer living in a rural region of northeast Japan noticed a nodule on her right ankle 5 years before her first visit to our hospital. She had a history of hypertension, hyperlipidemia, and osteoporosis, but had no history of trauma to her right ankle. The patient did not seek immediate medical attention, and the nodule gradually increased in size, after which she visited our hospital. A physical examination revealed a cystic mass of approximately $45 \times 30 \mathrm{~mm}$ at the tip of the right lateral malleolus (Fig. 1a). There was no tenderness, redness, or local heat. The patient had no functional impairment of her right ankle joint. Needle aspiration of the mass revealed accumulation of approximately $10 \mathrm{~mL}$ of yellowish white homogeneous fluid (Fig. 1b). Gram stain of the fluid revealed accumulated neutrophils and Gram-negative branching hyphae (Fig. 1c). X-ray images revealed osteoarthritis of the ankle joint. Magnetic

(c) The Author(s). 2018 Open Access This article is distributed under the terms of the Creative Commons Attribution 4.0 International License (http://creativecommons.org/licenses/by/4.0/) which permits unrestricted use, distribution, and reproduction in any medium, provided you give appropriate credit to the original author(s) and the source, provide a link to the Creative Commons license, and indicate if changes were made. The Creative Commons Public Domain Dedication waiver (http://creativecommons.org/publicdomain/zero/1.0/) applies to the data made available in this article, unless otherwise stated. 

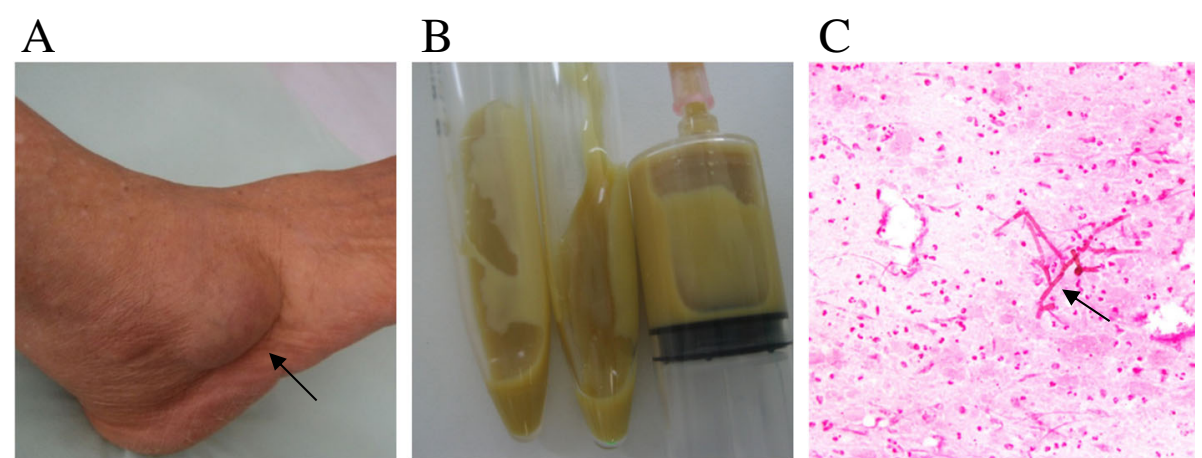

Fig. 1 Clinical pictures. a An image of the right ankle showing a $30 \times 45 \mathrm{~mm}$ nodule, b Aspiration of the nodule showing yellowish-white fluid, c Gram stain of the fluid showing accumulated neutrophils and Gram-negative branching hyphae (magnification of $\times 200$ )

resonance imaging (MRI) scan with contrast revealed a well-defined T1 iso-/T2 high-intensity mass with strong marginal enhancement on contrast imaging (Fig. 2). White blood cell count and serum C-reactive protein level were within the normal limit. Microscopic analysis of the fluid revealed no organism or crystal, like monosodium urate and calcium pyrophosphate. Culture of the aspirated fluid showed negative findings. After the initial visit, the patient discontinued the follow-up visits.

One year after the initial visit, the patient returned to our hospital because of pain in the right ankle joint. The mass did not appear to have changed in size. Aspiration of the fluid was repeated with no change in its characteristics. However, culture of the aspirated fluid revealed growth of black colonies (Fig. 3a). Microscopic analysis detected blackish hyphae (Fig. 3b, c). The fungus was classified as a branching group of Kirschsteiniothelia by sequencing the internal transcribed spacer (ITS) regions. A second aspiration performed 1 month later showed the same results on morphological and molecular biological examinations. The sensitivity patterns of antifungal agents were studied (Table 1). Fluid accumulation recurred shortly after needle aspiration; however, the patient became otherwise asymptomatic and refused further treatment, such as antimycotics or surgical debridement; the patient is currently under careful observation.

\section{Microbiological examination}

Growth of black colonies was obtained on Sabouraud dextrose agar (Purmedia, Eiken Chemical Co., Ltd., Tokyo, Japan) after 10 days of incubation at $25^{\circ} \mathrm{C}$ (Fig. 3a), and no growth was observed on blood agar/bromothymol blue lactose agar (TSA', Nippon Becton Dickinson Company, Ltd., Tokyo, Japan). Microscopic analysis revealed 2.5-3.0 $\mu \mathrm{m}$, brown to black, septate, smooth, or verrucose hyphae with dark brown droplets, which were blanching (Fig. 3b, c). There was no conidia or spore formation that would lead to species identification.

\section{Molecular examination}

The fungal DNA was extracted using PrepMan-Ultra Sample Preparation Reagent (Applied Biosystems, Foster City,
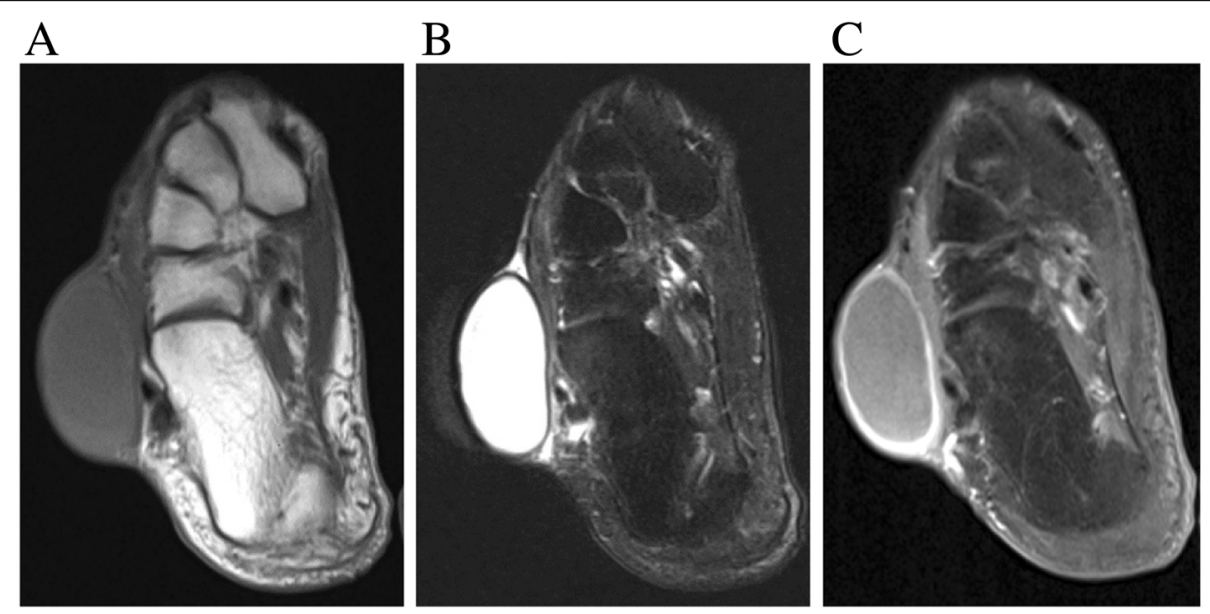

Fig. 2 Magnetic resonance imaging. a T1-weighted image showing iso-intensity mass, b T2-weighted image indicating high-intensity mass, c T1-weighted image with gadolinium contrast showing strong marginal enhancement 


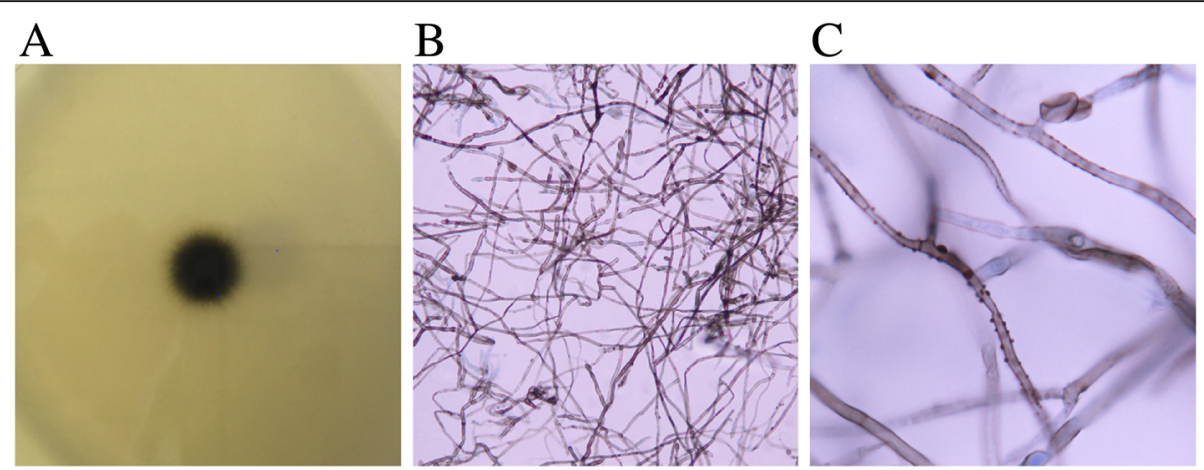

Fig. 3 Microbiological examination of the pathogen. a Picture of the Kirschsteiniothelia growing on Sabouraud dextrose agar, b Microscopic imaging of the fungus (magnification of $\times 400$ ), c Microscopic imaging of the fungus (magnification of $\times 1000$ )

CA) from the culture on potato dextrose agar $\left(\right.$ Difco $^{\text {Th }}$ Potato Dextrose Agar, Nippon Becton Dickinson Company, Ltd.) after 7 days of incubation at $25^{\circ} \mathrm{C}$. The ITS regions of fungal ribosomal DNA were amplified with primers ITS4 and ITS1 [3]. The sequence of the ITS region was determined using ABI Prism $3130 \mathrm{~N}^{\circ}$ (Applied Biosystems, Foster City, CA) (Additional file 1) and compared with other known species in the GenBank database using the Basic Local Alignment Search Tool (BLAST) algorithm [4] (Additional file 2). BLAST searches demonstrated 89-91\% identity matches with Kirschsteiniothelia and Dendryphiopsis species in the Kirschsteiniotheliaceae family (91\%, K. aethiops, Genbank no. AF377283.1; 91\%, Dendryphiopsis atra, Genbank no. HF677175.1; 90\%, K. lignicola, Genbank no. HQ441567.1; and 90\%, K. emarceis, Genbank no. NR_138375.1).

\section{Discussion and conclusions}

Black fungi are saprophytic in nature and mainly exist in soil, decaying plants, and trees worldwide. The typical form of black fungus infection is called chromoblastomycosis, which is characterized by chronic, progressive, cutaneous, and subcutaneous infection caused by black fungi. The most commonly infected organ in humans is the skin. The fungi usually invade the body through minor wounds; hence, the lesions are mostly found in

Table 1 Results of the antifungal susceptibility test

\begin{tabular}{ll}
\hline Antifungal agent & MICs $(\mu \mathrm{g} / \mathrm{mL})$ \\
\hline Micafungin & 0.5 \\
Caspofungin & 4 \\
Amphotericin B & $>16$ \\
Flucytocine & 0.12 \\
Fluconazole & 16 \\
Itraconazole & $>8$ \\
Voriconazole & $>8$ \\
Miconazole & 1
\end{tabular}

MIC minimum inhibitory concentration the exposed parts of the body. Infection in other internal organs, such as brain abscesses, were also reported mostly among immunocompromised patients [5], but are extremely rare in immunocompetent patients. Most patients with cutaneous black fungal infection are farmers, as was our patient [6], probably due to occupational exposure to plants and soil [7].

Three reports of black fungal bursitis were found in the English literature [8-10] (Table 2). A patient with olecranon bursitis had a long history of post-traumatic non-infectious bursitis at the olecranon, and the fungus infected the pre-existing fluid accumulated in the bursa. In our case, the microscopic analysis of fluid aspirated at her first visit showed negative findings. There are two possible explanations for this: the patient had only non-infectious bursitis at that time, or the causal fungus existed but was not cultured due to technical reasons. As the clinical course and symptoms of our patient at the first visit were compatible with non-infectious bursitis, we believe a superimposed infection was highly likely to have occurred in our case. All reported cases were in immunocompromised hosts due to chronic medical conditions who needed treatment with surgical debridement and antifungal medications. There was no report on black fungal bursitis among immunocompetent patients. The immune condition of our patient may have resulted in less severe symptoms and a long clinical course.

Kirschsteiniothelia was first identified from the class Dothideomycetes by Hawksworth et al. in 1985 [11]. Boonmee et al. revised its taxonomy and introduced the Kirschsteiniotheliaceae family using nucleotide sequence analysis in 2012 [12]. By 2017, 22 species of the Kirschsteiniotheliaceae family had been identified [13]. In Japan, Hosoya et al. reported that a species of the Kirschsteiniothelia genus was identified on wood in Yakushima Island (K. incrustans) [14]. Kirschsteiniothelia has been known to infect plants and is found in decaying trees, soil, and water worldwide, similar to several other black 
Table 2 Summary of reported cases of black fungal bursitis

\begin{tabular}{|c|c|c|c|c|c|c|}
\hline Reference & Sex/age & Major co-morbidities & Infection Site & Pathogen & Treatment & Country \\
\hline Padhye et al. (1995) [9] & $\mathrm{F} / 72$ & $\begin{array}{l}\text { Wegener's granulomatosis } \\
\text { (Prednisone, methotrexate) }\end{array}$ & Knee & Mycoleptodiscus indicus & Antifungal & USA \\
\hline Linas et al. (2005) [8] & $F / 54$ & MDS IgAD & Olecranon & Phaeoacremonium spp. & Excision, antifungal & USA \\
\hline $\begin{array}{l}\text { Almagro-Molto et al. } \\
\text { (2016) [10] }\end{array}$ & $\mathrm{F} / 55$ & $\begin{array}{l}\text { Post-kidney-pancreas transplantations } \\
\text { (Prednisone, tacrolimus) }\end{array}$ & Knee & Rousoella percutanea & Antifungal & Germany \\
\hline Nishi et al. (Presenting) & $F / 81$ & None & Ankle & Kirschsteiniothelia spp. & Aspiration & Japan \\
\hline
\end{tabular}

fungi; however, Kirschsteiniothelia infections in humans or animals have never been reported. In our case, repeated cultures of the fluid aspirate detected black colonies and blackish hyphae, which is consistent with the characteristics of other Kirschsteiniothelia spp. [12, 1518]. Later the diagnosis was confirmed by comparison analysis of the nucleotide sequence of the ITS region. Currently, molecular identification is an essential tool for the diagnoses of rare fungal infections, along with classical morphological identification; it has also contributed to the revision of the taxonomy of fungi [19], including Kirschsteiniothelia [12], as well as the discovery of novel species. Da Cunha et al. compared the DNA sequences of 101 clinical isolates of morphologically identified Curvularia spp. and reported that the species could not be confidently identified in over $25 \%$ of the isolates. The authors suggested that some isolates belonged to putative new species [20]. In our case, we could not obtain a perfect species match with the nucleotide sequence. Although not all known Kirschsteiniothelia species have been deposited in the GenBank database, it is possible that the causal fungus is a new species of Kirschsteiniothelia.

For treatment of black fungal infections, no standard therapy has been established, but previous studies demonstrated that voriconazole, posaconazole, and itraconazole presented in vitro activity against these infections [1]. Neither the standard assay of drug sensitivity nor its break point has been established for Kirschsteiniothelia. However, the pathogenic fungus did not appear to be inhibited in vitro with high concentrations of itraconazole and voriconazole (posaconazole was not examined); this implies that these agents may not be effective against Kirschsteiniothelia infection. In our case, no treatment was performed except aspiration of the accumulated fluid; therefore, we could not assess the in vivo efficacy of antifungal drugs. Further studies are needed to guide the indication and efficacy of antifungal drugs for Kirschsteiniothelia infection in humans.

Finally, most black fungus infections occur in immunocompromised hosts. We believe that the patient requires long-term observation because it is possible that similar symptoms may recur or that invasive disease may manifest in future if the patient's immune status deteriorates.
In conclusion, this is the first case report of human infection by Kirschsteiniothelia. The diagnosis was confirmed by repeated morphological and molecular analyses. This patient received no treatment except fluid aspiration; thus, long-term observation is mandatory and further studies are needed to establish the treatment strategy for this fungal infection.

\section{Additional files}

Additional file 1: Nucleoid sequence of the internal transcribed spacer region. (PPTX $45 \mathrm{~kb}$ )

Additional file 2: The result of molecular analysis with GenBank database using the Basic Local Alignment Search Tool (BLAST) algorithm

(Icl|Query_85557 is the specimen from the presenting patient). (PDF $100 \mathrm{~kb}$ )

\begin{abstract}
Abbreviations
BLAST: Basic Local Alignment Search Tool; ITS: the internal transcribed spacer; MRI: Magnetic Resonance Imaging
\end{abstract}

\section{Funding}

The authors received no financial support for the research, authorship, or publication of this article.

\section{Availability of data and materials}

The nucleotide sequencing data generated in this study was deposited in GenBank database under accession number MH251866. Other data that support the findings of this study are available from the corresponding author upon reasonable request.

\section{Authors' contributions}

MN conceptualized, collected and interpreted the clinical data, and wrote the manuscript. 10 interpreted the clinical data and wrote the manuscript. TY carried out the microbiological examination and nucleotide sequencing, interpreted the data, and wrote the manuscript. YH, KN, TS, and $\mathrm{KI}$ revised the manuscript critically for important content. All authors read and approved the final manuscript.

\section{Ethics approval and consent to participate}

Written informed consent was obtained from the patient. A statement of the ethics committee was not required for this anonymized case report, all in accordance with legislation of the Institutional Review Committee of OhtaNishinouchi Hospital.

\section{Consent for publication}

Written informed consent was obtained from the patient for the publication of this case report. A copy of the written consent is available for review by the Editor of this journal.

Competing interests

The authors declare that they have no competing interests. 


\section{Publisher's Note}

Springer Nature remains neutral with regard to jurisdictional claims in published maps and institutional affiliations.

\section{Author details}

'Department of OrthopaedicSurgery, Ohta-Nishinouchi Hospital, 2-5-20 Nishinouchi, Koriyama, Fukushima 963-8558, Japan. ${ }^{2}$ Department of Respiratory Medicine, Ohta-Nishinouchi Hospital, 2-5-20 Nishinouchi, Koriyama, Fukushima 963-8558, Japan. ${ }^{3}$ Department of Infection Control, Fukushima Medical University, 1 Hikarigaoka, Fukushima, Fukushima 960-1295, Japan. ${ }^{4}$ Department of Orthopaedic Surgery, Showa University School of Medicine, 1-5-8 Hatanodai, Shinagawa-ku, Tokyo 142-8666, Japan. ${ }^{5}$ Medical Mycology Research Center, Chiba University, 1-8-1 Inohana,

Chuo-ku, Chiba, Chiba 260-8673, Japan.

Received: 15 February 2018 Accepted: 15 May 2018

Published online: 22 May 2018

\section{References}

1. Chowdhary A, Meis JF, Guarro J, de Hoog GS, Kathuria S, Arendrup MC, et al. ESCMID and ECMM joint clinical guidelines for the diagnosis and management of systemic phaeohyphomycosis: diseases caused by black fungi. Clin Microbiol Infect. 2014;20:47-75.

2. De Hoog GS, Queiroz-Telles F, Haase G, Fernandez-Zeppenfeldt G, Attili Angelis D, Gerrits Van Den Ende AH, et al. Black fungi: clinical and pathogenic approaches. Med Mycol. 2000;38(Suppl 1):243-50.

3. White TJ, Bruns T, Lee S, Taylor J. Amplification and direct sequencing of fungal ribosomal RNA genes for phylogenetics. In: Innis M, Gelfand G, Sninsky J, and white T, editors. PCR protocols: a guide to methods and applications. Orlando: Academic Press; 1990. p. 315-22.

4. Zhang Z, Schwartz S, Wagner L, Miller W. A greedy algorithm for aligning DNA sequences. J Comput Biol. 2000;7(1-2):203-14.

5. Li DM, de Hoog GS. Cerebral phaeohyphomycosis-a cure at what lengths? Lancet Infect Dis. 2009;9(6):376-83.

6. Agarwal R, Singh G, Ghosh A, Verma KK, Pandey M, Xess I. Chromoblastomycosis in India: review of 169 cases. PLoS Negl Trop Dis. 2017;11(8):e0005534

7. Rossmann SN, Cernoch PL, Davis JR. Dematiaceous fungi are an increasing cause of human disease. Clin Infect Dis. 1996:22(1):73-80.

8. Llinas L, Olenginski TP, Bush D, Gotoff R, Weber V. Osteomyelitis resulting from chronic filamentous fungus olecranon bursitis. J Clin Rheumatol. 2005;11(5):280-2.

9. Padhye AA, Davis MS, Reddick A, Bell MF, Gearhart ED, Von Moll L. Mycoleptodiscus indicus: a new etiologic agent of phaeohyphomycosis. J Clin Microbiol. 1995;33(10):2796-7.

10. Almagro-Molto M, Haas A, Melcher C, Nam-Apostolopoulos YC, Schubert S. First case of Roussoella percutanea bursitis. Diagn Microbiol Infect Dis. 2017;87(2):172-4

11. Hawksworth DL. Kirschsteiniothelia, a new genus for the Microthelia incrustans-group (Dothideales). Bot J Linn Soc. 1985;91(1-2):181-202.

12. Boonmee S, Ko TWK, Chukeatirote E, Hyde KD, Chen H, Cai L, et al. Two new Kirschsteiniothelia species with Dendryphiopsis anamorphs cluster in Kirschsteiniotheliaceae fam. Nov. Mycologia. 2012;104(3): 698-714.

13. Index Fungorum. Index Fungorum Partnership. 2018. http://www.indexfun gorum.org/. Accessed 14 Feb 2018.

14. Hosoya T, Tanaka K. Ascomycetes and anamorphic fungi collected from Yakushima Island, southern Japan. Bull Natl Sci Mus Ser B. 2007;33:47-54.

15. Mehrabi M, Hemmati R, Asgari B. Kirschsteiniothelia arasbaranica sp. nov., and an emendation of the Kirschsteiniotheliaceae. Cryptogamie Mycol. 2017;38(1):13-25.

16. Chen $\mathrm{CY}$, Hsieh WH. On the type species of the genus Kirschsteiniothelia. K aethiops Sydowia. 2004;56(2):229-36.

17. Chen C, Wang C, Huang W. Two new species of Kirschsteiniothelia from Taiwan. Mycotaxon. 2006;98:153-8.

18. Zhang Y, Fournier J. Kirschsteiniothelia thujina (peck) D. Hawksw. (Kirschsteiniotheliaceae), reported from Europe for the first time. Ascomyceteorg. 2015;7(1):31-7.
19. Phookamsak R, Liu J-K, McKenzie EHC, Manamgoda DS, Ariyawansa H, Thambugala KM, et al. Revision of Phaeosphaeriaceae. Fungal Divers. 2014 68(1):159-238.

20. da Cunha KC, Sutton DA, Fothergill AW, Gene J, Cano J, Madrid H, et al. In vitro antifungal susceptibility and molecular identity of 99 clinical isolates of the opportunistic fungal genus Curvularia. Diagn Microbiol Infect Dis. 2013;76(2):168-74.

\section{Ready to submit your research? Choose BMC and benefit from:}

- fast, convenient online submission

- thorough peer review by experienced researchers in your field

- rapid publication on acceptance

- support for research data, including large and complex data types

- gold Open Access which fosters wider collaboration and increased citations

- maximum visibility for your research: over $100 \mathrm{M}$ website views per year

At BMC, research is always in progress.

Learn more biomedcentral.com/submissions 